

\title{
High diversity of invasive Haemophilus influenzae isolates in France and the emergence of resistance to third generation cephalosporins by alteration of ftsI gene
}

Ala-Eddine Deghmane, Eva Hong, Sara Chehboub, Aude Terrade, Michael Falguières, Morgan Sort, Odile B. Harrison, Keith A. Jolley, Muhamed-Kheir Taha

\section{To cite this version:}

Ala-Eddine Deghmane, Eva Hong, Sara Chehboub, Aude Terrade, Michael Falguières, et al.. High diversity of invasive Haemophilus influenzae isolates in France and the emergence of resistance to third generation cephalosporins by alteration of ftsI gene. Journal of Infection, 2019, 79 (1), pp.7-14. 10.1016/j.jinf.2019.05.007 . pasteur-02423493

\section{HAL Id: pasteur-02423493}

https: / hal-pasteur.archives-ouvertes.fr/pasteur-02423493

Submitted on 25 Oct 2021

HAL is a multi-disciplinary open access archive for the deposit and dissemination of scientific research documents, whether they are published or not. The documents may come from teaching and research institutions in France or abroad, or from public or private research centers.
L'archive ouverte pluridisciplinaire HAL, est destinée au dépôt et à la diffusion de documents scientifiques de niveau recherche, publiés ou non, émanant des établissements d'enseignement et de recherche français ou étrangers, des laboratoires publics ou privés.

\section{(ㄷ)(1) $\$$}

Distributed under a Creative Commons Attribution - NonCommerciall 4.0 International 
High diversity of invasive Haemophilus influenzae isolates in France and the emergence of resistance to third generation cephalosporins by alteration of $f t s I$ gene.

Ala-Eddine Deghmane ${ }^{\mathrm{a}}$, Eva Hong ${ }^{\mathrm{a}}$, Sara Chehboub ${ }^{\mathrm{a}}$, Aude Terrade ${ }^{\mathrm{a}}$, Michaël Falguières ${ }^{\mathrm{a}}$, Morgan Sort ${ }^{\mathrm{a}}$, Odile Harrison ${ }^{\mathrm{b}}$, Keith A. Jolley ${ }^{\mathrm{b}}$, and Muhamed-Kheir Taha ${ }^{\mathrm{a}^{*}}$

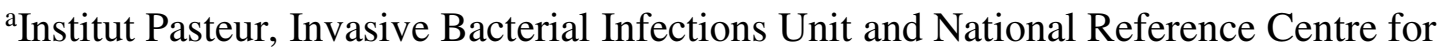
Meningococci and Haemophilus influenza, Paris, France

${ }^{\mathrm{b}}$ University of Oxford, Department of Zoology, Oxford, UK

*Corresponding Author: Muhamed-Kheir Taha

mktaha@pasteur.fr

Tel+3314568 8438

Keywords: Infection; Haemophilus influenzae; Typing; Whole genome sequencing; Antibiotic resistance

Running title: invasive Haemophilus influenzae infections 


\section{Abstract}

\section{Background}

3 Invasive infections due to Haemophilus influenzae are infrequent following the

4 implementation of vaccination against $H$. influenzae of serotype b. However, their changing 5 epidemiology may not be clear due to a lack of appropriate genotyping methods combined

6 with antibiotic susceptibility analyses which do not discriminate invasive and non-invasive

7 isolates. We aimed to describe recent epidemiological trends of invasive $H$. influenzae

8 infections in France and explore the microbiological characteristics of invasive versus non9 invasive isolates.

\section{Methods}

All culture- and PCR-confirmed cases due to $H$. influenzae isolated from a sterile site, that were received at the French national reference centre for $H$. influenzae during the year 2017 $(n=138)$ were characterized by whole genome sequencing (WGS), serotyping and antibiotic susceptibility testing. We also included 100 isolates that were received from non-invasive infections.

\section{Findings}

Most of the non-invasive isolates were non-typeable (99\%) and this proportion was significantly less among invasive isolates $75 \%, \mathrm{p}<0.0001)$. Serotype f was the most frequently observed but serotypes $\mathrm{b}$ and a were also present among invasive isolates. WGS analysis suggested a serotype b to a capsule switching event. Non-typeable isolates showed extensive heterogeneity. Antibiotic susceptibility testing indicated that $24 \%$ of the invasive isolates were resistant to ampicillin but this percentage was significantly higher $(51 \%, \mathrm{p}<0.001)$ among the non-invasive isolates. Moreover, the proportion of beta-lactamase negative ampicillin resistant isolates (BLNAR) was significantly higher among non-invasive isolates 
compared to that of invasive isolates $(24 \%$ versus $7 \%, \mathrm{p}<0.001)$. BLNAR isolates were linked to modification in the ftsI gene encoding the penicillin binding protein 3 (PBP3). In particular, ftsI alleles that harboured the mutations D350N, S357N, M377I and S385T were resistant to ampicillin and third generation cephalosporins. These isolates were more frequent among non-invasive isolates.

\section{Interpretation}

Our data suggest that invasive $H$. influenzae isolates differed phenotypically and genotypically from non-invasive isolates. The high proportion of ampicillin resistance by mutation in ftsI among non-invasive isolates may suggest a biological cost of these mutations on the function of PBP3 that can lead to lower bacterial invasiveness. WGS should be used routinely for the characterization of $H$. influenzae isolates in order to reliably follow the emergence, spread and mechanism of antibiotic resistance.

(1)

39

0

41

42

43

4

45




\section{Introduction}

Haemophilus influenzae (Hi) is a coccobacillus Gram negative bacterium that is most frequently encountered at the mucosal surfaces in humans (mainly respiratory pathways). Hi can provoke local infections at these mucosal surfaces such as otitis media, conjunctivitis, sinusitis and also genitourinary infections (1). Moreover, invasive $H$. influenzae invasive disease (IHiD) occurs when Hi invade the bloodstream and then spread to other distal organs. In Europe, the usual forms of IHiD are septicaemia. However, meningitis and more rarely, invasive pneumonia, epiglottitis, arthritis/osteomyelitis are reported (2-4).

Hi isolates are divided into two broad categories: encapsulated and non-encapsulated isolates. Capsule structure and antigenicity determine the serotype. Of the six identified serotypes (a to f), Hi of serotype b (Hib) is the most pathogenic in humans, affecting mainly infants and young children. The introduction of the serotype b conjugate vaccine in the 1990s resulted in a considerable decline in the incidence of invasive Hib infections and reduced circulation of Hib isolates. The other serotypes (a, c, d, e and f) are less frequently associated with IHiD although serotype a is emerging in the USA and Canada $(5,6)$. Non-encapsulated strains also called "non-typeable" $\mathrm{Hi}$ (NTHi), cause usually non-invasive infections of the upper respiratory tract, but can also be responsible for invasive infections (7). Asymptomatic carriage of NTHi strains in healthy children under 5 years of age is common $(27.7 \%$ with a variation between $73.2 \%$ in winter and $26.8 \%$ in summer) (8). Carriage of encapsulated strains is rarer especially carriage of Hib in countries where Hib vaccination is included into national immunization schedules (9). In Europe, the total number of cases of IHiD was 2799 in 2014 (61\% with a known serotype) with a trend to increasing numbers of reported cases from 2010 to $2014(3,4)$. The incidence is higher in infants (4 cases for 100,000) and in older adults (1.7 cases for 100,000$)$. 
In Europe in 2014, 6\% of the cases with a known serotype were Hib, of which 57\% were aged 25 years and older. Non-encapsulated strains caused the majority of cases in all age groups ( $82 \%$ of all cases for which serotyping results were available). Serotype f caused $9 \%$ of all cases and $72 \%$ of cases among non-B serotypes (serotypes a, c, d, e, and f) (4). The increase in the incidence of IHiD that is observed in Europe appears to be due to the increase in invasive NTHi and Hi infections in individuals over 60 years of age. These patients are not immunocompromized and yet they develop severe infections (10). Recent data suggest increasing virulence of these NTHi isolates as well as the acquisition of resistance to several antibiotics. In particular, resistance to beta-lactams seems to be driven by both the acquisition of a beta-lactamase and/or acquisition of well characterized mutations in the penicillinbinding-protein 3 (PBP3 encoded by the ftsI gene) (11). However, these isolates remained most frequently susceptible to third-generation cephalosporins. Resistance to third-generation cephalosporins was reported and suggested to be due to the acquisition of TEM-15 betalactamase, but the role of mutations in PBP3 is still unclear (12). Our aim was to screen all Hi isolates received at the French National Reference Centre for meningococci and Haemophilus influenzae during the year 2017 and characterize resistance to third-generation cephalosporins by whole genome sequencing.

(1)

4

5

6

7

8

99

00

\section{(1)}




\section{Methods}

\section{Culture conditions and identification of $\boldsymbol{H}$. influenzae.}

IHiD reporting is not mandatory in France and sentinel surveillance is part of surveillance for invasive bacterial infections. IHiD is defined by the detection of Hi in a sterile site (such as blood, cerebrospinal fluid (CSF), or synovial fluid) by culture and/or PCR. Isolates that areidentified as $H$. influenzae by hospitals can be sent to the National Reference Centre for meningococci and Haemophilus influenzae (NRCMHi) at the Institut Pasteur, Paris for further typing. Isolates were cultured on chocolate agar plates (BioMérieux, Marcy l'Etoile, France) and identification was confirmed based on the requirement for heme and NAD for growth on ordinary medium. In addition, a molecular identification algorithm was set up on the basis of PCR-amplification of four common genes ( $h p d$, ompP2, bexA, fucK,) (13). PCR-based prediction of serotypes $\mathrm{a}, \mathrm{b}, \mathrm{c}, \mathrm{d}$, e and $\mathrm{f}$ was also performed for each strain (14). A typeable isolate was identified as positive by PCR for the five common genes and one of the serotypespecific genes. Non-typeable isolates were identified as positive by PCR for four of the common genes and negative for bexA gene and all of the serotype-specific PCRs (14). Realtime PCR was used to confirm the diagnosis of IHiD by the detection of the hpd gene and the specific gene for the six serotypes for non-culture cases (15). All of the primers used in this study are listed in the Supplementary Table 1

\section{Antibiotic susceptibility testing}

Susceptibility and resistance to antibiotics was performed using MHF agar plates (BioRad, Marnes-la-Coquette, France) and Etest strips (BioMérieux, Marcy l'Etoile, France). Critical values (breakpoints) were set according to the recommendation of the EU-CAST. Betalactams tested were ampicillin, amoxicillin+clavulanic acid and third generation cephalosporins (cefotaxim). Susceptibility to meropenem was occasionally performed upon the detection of resistance to cefotaxim. 


\section{Whole genome sequencing}

128

129

130

131

132

133

134

135

136

137

138

WGS was performed systematically on all invasive cultured isolates received at the NRCMHi. Genomic DNA was extracted with the MagNA Pure 96 system (Roche Molecular System, Pleasanton, USA). Library preparation were performed with the Nextera ${ }^{\circledR}$ XT DNA library Preparation Kit (Illumina, San Diego, USA) and whole genome sequencing was processed with Illumina technology (NextSeq 500, Illumina) with paired-end strands of 150 bp and a sequencing depth of 50X. All de novo assemblies were generated using SPAdes 3.10 (CAB, St. Petersburg State University, Russia). Sequences are available through the PubMLST https://pubmlst.org/hinfluenzae/_database (16). WGS data were used to infer sequence types (ST) according to the Multilocus Sequence Typing (MLST) scheme (17) WGS data were also analysed using a "gene-by-gene" approach using the annotated reference strain (Rd KW20) on the Bacterial Isolate Genome Sequence Database (BIGSdb) platform on PubMLST (18). SplitsTree4 (version 4.14.6) was used to visualise the resulting distance matrices as Neighbour-net networks. (19) GrapeTree was also drawn on the basis of comparisons of allelic profiles for the isolates with complete MLST data (20). IDs of all these isolates are given in the supplementary Table 2 to allow retrieving of WGS sequences in FASTA formats as well as the ENA accession numbers (project accession $\mathrm{N}^{\circ}$ PRJEB28646).

\section{Molecular analysis of the ftsI gene}

Sequences of a 621-bp fragment of ftsI gene (encoding the PBP3), corresponding to nucleotides 977-1597 relative to the ftsI start codon, were used to assign alleles for the corresponding isolates through the PubMLST database and analysed through the tools available on the BIGSdb platform. Sequences were aligned using Multiple Sequence Alignment by CLUSTALW and sequences differing by at least one nucleotide were assigned 
150 a unique ftsI allele sequence number. Phylogenetic networks were generated using SplitsTree 151 (version 4.14.6) (www.splitstree.org) with default parameters (19).

\section{Data analysis}

153 Proportions were compared using Chi-square test or Fisher exact test using the threshold of $p$ 154 value $<0.05$ as statistically significant.

155

156

157

158

159

160

161

162

163

164

165

166

167

168

169 


\section{Description of the isolates}

172 During the year 2017, the NRCMHi received a total of $236 \mathrm{Hi}$ cultured isolates in addition to

1732 CSF that were confirmed only by PCR. There were 100 cultured isolates from non-invasive 174 sites of which $(88 \% 100,88 \%)$ isolates were from respiratory sites (including nasopharynx, 175 sinus, ear and conjunctiva) and 12 isolates were from genito-urinary sites (most frequently vagina). Most of these non-invasive isolates $(74 / 100 ; 74 \%)$ were from adults. All the non-

177 invasive isolates were non-typeable except one isolate of serotype f.

There were 138 invasive cases (136 invasive cultured isolates and 2 non-culture PCRconfirmed cases) that were mainly confirmed from blood $(96 / 138 ; 70 \%)$ and CSF $(36 / 138$; $26 \%)$. The remaining isolates $(6 / 138 ; 4 \%)$ were from synovial fluid, peritoneal fluid and organ biopsies. Most of the cases $(84 / 138 ; 61 \%)$ were among children <5 years of age $(40 / 138 ; 29 \%)$ and among adults > 64 years $(44 / 138 ; 32 \%)$. The male-to-female ratio was

1.3:1. Age and serotype distributions of invasive isolates are depicted in Fig.1. Most of the cases corresponded to non-typeable isolates $(103 / 138 ; 75 \%)$ and $35 / 148$ invasive cases were typeable $(25 \%, \mathrm{p}<0.0001$ when compared to $1 \%$ of the non-invasive isolates). Detected serotypes were serotype a (Hia $n=7$ mainly among children $<5$ years) serotype $b($ Hib $n=10)$, serotype $d$ (Hid $n=1$ ), serotype e (Hie $n=5$ of which 1 case was PCR-confirmed only) and serotype $\mathrm{f}$ (Hif $\mathrm{n}=12$ ). Serotypeable isolates were more likely to be detected under the age of 5 years than other age groups $(17 / 40 ; 43 \%$ versus $10 / 4423 \%$; $=0.018)$.

\section{Antibiotic susceptibility testing}

Among the 136 invasive cultured isolates, $(104 / 136 ; 76 \%)$ were beta lactamase negative ampicillin susceptible (BLNAS), $(23 / 136 ; 17 \%)$ were beta lactamase positive ampicillin resistant (BLPAR) and $(9 / 136 ; 7 \%)$ were beta lactamase negative ampicillin resistant 
(BLNAR) (Table 1). Invasive typeable isolates were more frequent among BLNAS isolates (30/104; $29 \%$ of all BLNAS invasive isolates were typeable) than BLPAR or BLNAR (4/32; $13 \%$ of all BLPAR and BLNAR invasive isolates were typeable) although this difference was not significant. It is noteworthy that none of the invasive typeable isolates were BLNAR and all the 4 ampicillin resistant typeable isolates (2 Hib and 2 Hie) were BLPAR (Table 1). Of interest, 8 invasive isolates were resistant to cefotaxim (MIC $>0.125 \mathrm{mg} / \mathrm{L}$ ). These isolates were BLNAS $(n=2)$, BLPAR $(n=2)$ and BLNAR $(n=4)$. They were all nontypeable except two isolates of serotype b (BLPAR) and e (BLNAS).

Antibiotic susceptibility testing showed that only 49 of the non-invasive isolates were susceptible to ampicillin with no detection of beta lactamase (BLNAS). However, 51 of the non-invasive isolates were resistant to ampicillin (MIC>1 mg/L). The proportion of ampicillin resistant isolates was significantly higher among non-invasive isolates compared to invasive isolates $(51 / 100 ; 51 \%$ versus $32 / 136 ; 24 \%$ respectively, $\mathrm{p}<0.001)$. Among the 51 ampicillin resistant non-invasive isolates, 27 isolates produced detectable beta-lactamase (BLPAR) and 24 did not (BLNAR). All these ampicillin resistant non-invasive isolates were NTHi while the serotype f non-invasive isolate was susceptible to all beta-lactams tested. Of interest, 29 noninvasive isolates were resistant to cefotaxim (MIC $>0.125 \mathrm{mg} / \mathrm{L}$ ). These isolates were BLNAS $(n=4)$, BLPAR $(n=9)$ and BLNAR $(n=16)$. The proportions of BLNAS and BLNAR, but not that of BLPAR, differed significantly between the non-invasive and invasive isolates ( $\mathrm{p}=0.0111, \mathrm{p}=0.0002$ and $\mathrm{p}=0.1683$ respectively). Serotyping and antibiotic susceptibility testing clearly suggest that invasive and non-invasive isolates differed significantly.

\section{Genomic analysis of the invasive isolates}

We next focused on the genetic typing of the isolates. Whole genome sequences (Illumina) were obtained for 130 of the 136 invasive cultured isolates (96\%) and complete MLST schemes were retrieved for (126/130 isolates; $97 \%$ of all isolates with WGS data), while 
partial MLST profiles were obtained for the 4 other isolates. There were 73 different STs identified among the 126 invasive isolates with ST-124 the most frequent $(n=10)$ followed by ST-6 $(n=8)$ and ST-388 $(n=5)$.

MLST data were also obtained for 34 of the 100 non-invasive isolates and these belonged to 27 different STs. GrapeTree analysis using MLST allelic profiles is depicted in Fig. 2. The ST were divers and were represented by no more than three isolates (for ST-107), which was distinct to the non-invasive isolates, with only 14 STs shared with the invasive isolates (STs $1,3,12,57,124,155,159,160,266,388,396,513,836$ and 1877) (Fig. 2). Several of these "mixed" nodes were composed of only BLPAR isolates (STs 160, 388 and 836). Serotype b isolates were all invasive and located in two clusters one of which containing most of the Hib isolates (ST-6 and ST-95). Interestingly, one serotype a isolate was ST-6 and clustered with serotype $b$ isolates suggesting a possible $b$ to a capsule switching event and genetic recombination between serotype a and b isolates. All of the other serotype a isolates clustered separately and were predominantly ST-23 $(n=3)$. Serotype f isolates clustered together with more homogeneity (Fig. 2).

These results suggest a lack of correlation between serotype and genetic lineage among invasive isolates. These data also indicate that non-invasive isolates differed from invasive isolates not only phenotypically but also by MLST.

We next analysed WGS data from the 130 invasive isolates using the "Genome Comparator" tool on PubMLST (16) and using the serogtype d strain $H$. influenzae Rd KW20 as a reference (21). The neighbour network showed a highly diverse non-typeable bacterial population and to a lesser extent for typeable isolates (Fig. 3). Much more resolution was obtained compared to the MLST analysis as several identical sequence types were further separated into different related nodes. The serotype a isolate (ST-6) was clustered with the other ST-6 isolates of serotype b. Moreover, serotype a and b isolates (ST-6) (Fig. 3). 


\section{Sequence data of $f t s I$}

246

A $621 \mathrm{bp}$ nucleotide sequence fragment of the ftsI gene was extracted for 131 of the invasive isolates. This segment of $f t s I$ corresponds to the region between the codons 326 and 533 that includes the DNA sequences encoding the three functional motifs of the PBP3: STVK, SSN, and KTG that start at positions 327, 379 and 512 respectively. These sequences allowed the identification of 43 different $f t s I$ alleles that were named ftsIn where $n$ is the number of the allele. Frequencies of isolates harbouring theses alleles varied from 1 to 20 isolates per allele and are available through the link https://pubmlst.org/hinfluenzae/ through the sequence query drop menu. These 43 alleles corresponded to 21 different amino-acid sequences (Table 2).

The phylogenetic tree drawn by SplitsTree4 was based on the CLUSTALW DNA sequence alignment of these $43 \mathrm{ftsI}$ alleles and indicates a clustering of these alleles into 4 groups (Fig. 4, each group is referred by a colour). Group 1 contained the two most frequent alleles ftsIIO and ftsI8 (20 and 15 isolates respectively). These two alleles shared $99.5 \%$ sequence identity (3 polymorphic sites). Moreover, translated amino acid sequences were identical for both alleles and this protein sequence was also identical for 13 other $f t s I$ alleles (Fig. 4). These 15 alleles were present in $(74 / 131 ; 56 \%)$ isolates that belonged to different genetic groups and different serotypes ( $\mathrm{a}, \mathrm{b}$ and $\mathrm{d}$ as well as among non-typeable isolates). The unique amino acid sequence for all these 15 alleles showed no known modification associated with nonbeta-lactamase mediated resistance to ampicillin. However, 14 isolates harboured a betalactamase and were therefore (BLPAR). The remaining 60 isolates were all BLNAS with MIC ranging between 0.016 and $0.5 \mathrm{mg} / \mathrm{L}$ (Table 3). All isolates were susceptible to third generation cephalosporins.

Group 2 consisted of $11 \mathrm{ftsI}$ alleles which clustered together on the phylogenetic tree separately from Group 1 . These 11 alleles corresponded to 6 unique amino-acid sequences 
that were shared by 31 invasive isolates $(31 / 131 ; 24 \%)$. Isolates were of different phenotypes (non-typeable and serotypes e and f) and belonged to different STs. Five of these isolates also harboured a beta-lactamase (BLPAR). The 26 isolates that were negative for the betalactamase were also all susceptible to ampicillin (BLNAS). Indeed, the MIC of ampicillin for these 26 isolates ranged from $0.032 \mathrm{mg} / \mathrm{L}$ to $0.5 \mathrm{mg} / \mathrm{L}$ (Table 3). All isolates were susceptible to third generation cephalosporins. The PBP3 amino acid sequences of this group harboured one of the following alterations D350N, A368T, A437S, A502T, and R517H but the alleles ftsI50 and ftsI94 harboured two alterations (D350N, A437S and D350N, R517H) respectively. However, no alleles showed alteration at the position N526.

Group 3 was composed of ftsI 10 alleles that corresponded to 8 unique amino-acid sequences shared by 17 invasive isolates $(17 / 131 ; 13 \%)$. Isolates were all non-typeable but belonged to different STs. All of these amino-acid sequences showed a N526K alteration with other variably present alterations. One isolate also harboured a beta-lactamase (BLPAR). The 16 other isolates that were negative for the beta-lactamase showed MIC of ampicillin ranging from $0.190 \mathrm{mg} / \mathrm{L}$ to $2 \mathrm{mg} / \mathrm{L}$ (Table 3). They were BLNAS (11/16 with MIC of ampicillin ranging between 0.380 and $1 \mathrm{mg} / \mathrm{L}$ ) and 5/16 isolates were BLNAR (MIC of ampicillin >1 $\mathrm{mg} / \mathrm{L}$ and ranged between 1.5 to $2 \mathrm{mg} / \mathrm{L}$ ). These five isolates harboured ftsIl, ftsI5, ftsI 21 or ftsI42. All of the 17 isolates in this group were susceptible to third generation cephalosporins (Table 3).

Finally, group 4 was also identified on the ftsI-based phylogenetic tree. This group contained 7 highly diverse $f t s I$ alleles when compared to the other alleles. These 7 alleles corresponded to 6 unique amino-acid sequences that were shared by 9 invasive isolates $(9 / 131 ; 7 \%)$. The isolates belonged to 8 different STs and were non-typeable but two were of serotypes b or e. Two of these 9 isolates were BLPAR while the 7 other isolates were BLNAS $(n=3)$ and BLNAR ( $n=4)$. All 9 isolates of this group were resistant to third generation cephalosporins 
294 (MIC >0.125 mg/L) (Table 3). All these PBP3 encoded by these 7 alleles showed the

295 following four mutations (D350N, S357N, M377I and S385T) with other mutations that were

296 variably present including the N526K mutation (Table 2 ). These isolates were heterogeneous

297 and corresponded to several genotypes (indicated by arrows in Fig. 3).

298 We also obtained $57 \mathrm{ftsI}$ sequences from carriage isolates that were distributed among 36

299 different $f t s I$ alleles of which 17 were only found among carriage isolates. The alleles were

300 represented by no more than 4 isolates ( 4 isolates for $f t s I 10$ and ftsI19). The four groups

301 described among the invasive isolates were also observed among non-invasive isolates but

302 with different proportions for group 1 to group 4 that were respectively $30 \%, 3 \%, 23 \%$ and

$30344 \%$. All the isolates were susceptible to meropenem including those that were resistant to

304 cefotaxime.

305

306

307

308

309

310

311

312

313

314

315

316

317 


\section{Discussion}

319 IHiD has become rare since the introduction of the conjugate vaccine against Hib. The incidence in Europe is around 0.49 per 100,000 population. By extrapolation to the French population we expect that the $138 \mathrm{IHiD}$ that we characterized in the present work represent around $40 \%$ of all IHiD cases. Age and sex distributions were similar to other European countries with higher number of cases in children under five years and in adults aged 65 years or older. The non-typeable isolates were the most frequent in all age groups as also reported in Europe (4) .

Moreover, non-invasive infection mainly in the upper respiratory tract infections and otitis media are frequent. Our data clearly suggest that the distribution of serotypes and antibiotic susceptibility profiles were significantly different between invasive and non-invasive infections. This was further strengthened by the MLST data. These observations warrant separate typing and analysis of Hi isolates. Serotypeable isolates are almost exclusively encountered among invasive isolates and were less diverse than non-typeable isolates as suggested by MLST and WGS analysis. This is in line with previous observations by MLST that suggested that the impact of recombination is greater among non-typeable than encapsulated isolates explaining the high diversity of these isolates(17). Serotype $f$ was the most frequent. However, it is worthy to underline the presence of serotype a of the sequence type ST-23 that was mostly among < 5 years of age as reported in Alaska and in Canada (5, 6). A serotype a isolate (isolated from an adult >64 years) shared the same ST (ST-6) as Hib

338 isolates and was also linked to those isolates on the basis of WGS analysis. Our data also 339 suggest frequent DNA recombination between isolates of serotypes a and b as also suggested by the neighbour network on the basis of WGS analysis. Implementation of routine WGS is therefore warranted to perform thorough surveillance and detect events such as the capsule 342 switching. 
Additionally, the proportion of BLNAS isolates differed significantly between invasive and non-invasive isolates $(76 \%$ versus $49 \% \mathrm{p}=0.011)$. This difference may reflect the selective pressure by repeated exposure of non-invasive isolates to antibiotics in the respiratory tract. However, the BLPAR did not significantly differ between the two groups of isolates while the proportions of BLNAR did. Indeed, BLNAR isolates were significantly less frequently encountered among invasive isolates (Table 2). BLNAR isolates usually harbour modifications of $f t s I$ encoding the PBP3 that is involved in the biosynthesis of peptidoglycan (PG) catalysing peptide cross-linking of PG chains. PBP3 is therefore an essential protein for cell division (divisome) (22). Modifications of PBP3 impact on the structure of PG that is a microbe associated molecular pattern (MAMP). These observations are in favour of biological cost of the modifications of ftsI gene encoding the PBP3 that can lead to lower bacterial invasiveness. This has been suggested for the modifications of PBP2 in Neisseria meningitidis that is also involved in PG cross-linking (23). PBP2 modifications in N. meningitidis is also responsible for reduced susceptibility to penicillin $\mathrm{G}$, a phenotype that is more frequently observed among non-invasive isolates (24).

Our ftsI sequence data shed new light on the correlation of the mutations of this gene and the resistance to beta-lactam antibiotics. The role of the mutations in the region close to the three functional motifs of the PBP3(STVK, SSN, and KTG) needs to be evaluated among betalactamase negative isolates. We further suggest a classification based on the correlation of the amino acid sequence of PBP3 and the geometric mean of the MIC of ampicillin for isolates in each of the four phylogenetic groups identified on the basis of ftsI sequence. Our data suggest that mutations in PBP3 have a cumulated effect to raise the MIC of ampicillin. However, several mutations when present alone (D350N, A368T, A437S, A520T, and R517H) or in combination of 2 mutations (D350N and A437S or D350N and R517H) did not confer 
resistance to ampicillin. Indeed our group 2 corresponds to the group 1 according to the classification of Ubukata and Dabernat $(25,26)$.

Our data suggest that the mutation N526K (that was absent in the second group) is necessary to confer resistance to ampicillin. The presence of other mutation (particularly A502V) was not consistent. Isolates of this third group showed significant increase in their MIC of ampicillin and we suggest this group to correspond to BLNAR.

The forth group corresponded to isolates that all harboured the following three mutations D350N, S357N and M377 and showed BLNAR phenotype that was also associated with resistance to third generation cephalosporins that we suggest to be named beta lactamase negative ampicillin and cephalosporin resistance isolates (BLNACR). The high proportions of ampicillin resistant isolates among both invasive and non-invasive isolates (24\% and 51\% respectively) may suggest that the use of ampicillin or amoxicillin as a first line treatment in Haemophilus infections (e.g; acute otitis media, AOM) is not supported by the molecular and phenotypic data in this study (27). Indeed, NTHi was reported to be the most frequent agent in AOM after the introduction of the 13-Valent Pneumococcal Conjugate Vaccine (28). However, the surveillance of these isolates and the surveillance of the emergence of the resistance to third generation cephalosporins require the use of molecular tools (ftsI sequencing) in addition to the antibiotic susceptibility testing in order to reliably characterize these isolates. 


\section{Acknowledgements}

This publication made use of the Haemophilus influenzae Multi Locus Sequence Typing website (https://pubmlst.org/) developed by Keith Jolley and sited at the University of Oxford(18). The development of this site has been funded by the Wellcome Trust. We also acknowledge the PIBNET-P2M platform at the Institut Pasteur. This work was funded by The Institut Pasteur and Santé Publique France. 


\section{References}

1. Casin I, Sanson-Le Pors MJ, Felten A, Perol Y. Biotypes, serotypes, and susceptibility to antibiotics of 60 Haemophilus influenzae strains from genitourinary tracts. Genitourin Med. 1988 Jun;64(3):185-8. PubMed PMID: 2970427. Pubmed Central PMCID: 1194197. Epub 1988/06/01. eng. 2. Takala AK, Eskola J, Peltola H, Makela PH. Epidemiology of invasive Haemophilus influenzae type $b$ disease among children in Finland before vaccination with Haemophilus influenzae type $b$ conjugate vaccine. Pediatr Infect Dis J. 1989 May;8(5):297-302. PubMed PMID: 2657619. Epub 1989/05/01. eng.

3. ECDC. Surveillance of invasive bacterial diseases in Europe, 2012. Stockholm: ECDC, 2015. 4. ECDC. European Centre for Disease Prevention and Control. Annual Epidemiological Report 2016 - Invasive Haemophilus influenzae disease. Stockholm: ECDC, 2016.

5. Bruce MG, Deeks SL, Zulz T, Navarro C, Palacios C, Case C, et al. Epidemiology of Haemophilus influenzae serotype a, North American Arctic, 2000-2005. Emerg Infect Dis. 2008 Jan;14(1):48-55. PubMed PMID: 18258076. Pubmed Central PMCID: 2600153. Epub 2008/02/09. eng.

6. Soeters HM, Blain A, Pondo T, Doman B, Farley MM, Harrison LH, et al. Current Epidemiology and Trends in Invasive Haemophilus influenzae Disease-United States, 2009-2015. Clin Infect Dis. 2018 Aug 31;67(6):881-9. PubMed PMID: 29509834. Epub 2018/03/07. eng.

7. Murphy TF, Faden H, Bakaletz LO, Kyd JM, Forsgren A, Campos J, et al. Nontypeable Haemophilus influenzae as a pathogen in children. Pediatr Infect Dis J. 2009 Jan;28(1):43-8. PubMed PMID: 19057458. Epub 2008/12/06. eng.

8. Ortiz-Romero MDM, Espejo-Garcia MP, Alfayate-Miguelez S, Ruiz-Lopez FJ, ZapataHernandez D, Gonzalez-Pacanowska AJ. Epidemiology of Nasopharyngeal Carriage by Haemophilus influenzae in Healthy Children: A Study in the Mediterranean Coast Region. Pediatr Infect Dis J. 2017 Oct;36(10):919-23. PubMed PMID: 28472007. Epub 2017/05/05. eng.

9. Hammitt LL, Crane RJ, Karani A, Mutuku A, Morpeth SC, Burbidge P, et al. Effect of Haemophilus influenzae type $\mathrm{b}$ vaccination without a booster dose on invasive $\mathrm{H}$ influenzae type $\mathrm{b}$ disease, nasopharyngeal carriage, and population immunity in Kilifi, Kenya: a 15-year regional surveillance study. Lancet Glob Health. 2016 Mar;4(3):e185-94. PubMed PMID: 26853149. Pubmed Central PMCID: 4763163. Epub 2016/02/09. eng.

10. Resman F, Ristovski M, Ahl J, Forsgren A, Gilsdorf JR, Jasir A, et al. Invasive disease caused by Haemophilus influenzae in Sweden 1997-2009; evidence of increasing incidence and clinical burden of non-type b strains. Clin Microbiol Infect. 2011 Nov;17(11):1638-45. PubMed PMID: 21054663. Epub 2010/11/09. eng.

11. Mansson V, Skaare D, Riesbeck K, Resman F. The spread and clinical impact of ST14CC-PBP3 type IIb/A, a clonal group of non-typeable Haemophilus influenzae with chromosomally mediated beta-lactam resistance-a prospective observational study. Clin Microbiol Infect. 2017 Mar;23(3):209 e1- e7. PubMed PMID: 27852000. Epub 2016/11/17. eng.

12. Caierao J, Sant'Anna FH, Hawkins P, Cunha GR, Mott M, Falci DR, et al. Characteristics of serogroup 20 S.pneumoniae isolates from Brazil. BMC Infect Dis. 2016 Aug 15;16(1):418. PubMed PMID: 27527077. Pubmed Central PMCID: 4986405. Epub 2016/08/17. eng.

13. Binks MJ, Temple B, Kirkham LA, Wiertsema SP, Dunne EM, Richmond PC, et al. Molecular surveillance of true nontypeable Haemophilus influenzae: an evaluation of PCR screening assays. PLoS One. 2012;7(3):e34083. PubMed PMID: 22470516. Pubmed Central PMCID: 3314702. Epub 2012/04/04. eng.

14. Falla TJ, Crook DW, Brophy LN, Maskell D, Kroll JS, Moxon ER. PCR for capsular typing of Haemophilus influenzae. J Clin Microbiol. 1994 Oct;32(10):2382-6. PubMed PMID: 7814470.

15. Wang X, Mair R, Hatcher C, Theodore MJ, Edmond K, Wu HM, et al. Detection of bacterial pathogens in Mongolia meningitis surveillance with a new real-time PCR assay to detect Haemophilus influenzae. Int J Med Microbiol. 2011 Apr;301(4):303-9. PubMed PMID: 21276750. Epub 2011/02/01. eng. 
16. Jolley KA, Bray JE, Maiden MCJ. Open-access bacterial population genomics: BIGSdb software, the PubMLST.org website and their applications. Wellcome Open Res. 2018;3:124. PubMed PMID: 30345391. Pubmed Central PMCID: 6192448. Epub 2018/10/23. eng.

17. Meats E, Feil EJ, Stringer S, Cody AJ, Goldstein R, Kroll JS, et al. Characterization of encapsulated and noncapsulated Haemophilus influenzae and determination of phylogenetic relationships by multilocus sequence typing. J Clin Microbiol. 2003 Apr;41(4):1623-36. PubMed PMID: 12682154.

18. Jolley KA, Maiden MC. BIGSdb: Scalable analysis of bacterial genome variation at the population level. BMC Bioinformatics. 2010;11:595. PubMed PMID: 21143983. Pubmed Central PMCID: 3004885. Epub 2010/12/15. eng.

19. Huson DH, Bryant D. Application of phylogenetic networks in evolutionary studies. Mol Biol Evol. 2006 Feb;23(2):254-67. PubMed PMID: 16221896.

20. Zhou Z, Alikhan NF, Sergeant MJ, Luhmann N, Vaz C, Francisco AP, et al. GrapeTree: visualization of core genomic relationships among 100,000 bacterial pathogens. Genome Res. 2018 Sep;28(9):1395-404. PubMed PMID: 30049790. Pubmed Central PMCID: 6120633. Epub 2018/07/28. eng.

21. Fleischmann RD, Adams MD, White O, Clayton RA, Kirkness EF, Kerlavage AR, et al. Wholegenome random sequencing and assembly of Haemophilus influenzae Rd. Science. $1995 \mathrm{Jul}$ 28;269(5223):496-512. PubMed PMID: 7542800. Epub 1995/07/28. eng.

22. Sauvage E, Kerff F, Terrak M, Ayala JA, Charlier P. The penicillin-binding proteins: structure and role in peptidoglycan biosynthesis. FEMS Microbiol Rev. 2008 Mar;32(2):234-58. PubMed PMID: 18266856.

23. Zarantonelli ML, Skoczynska A, Antignac A, El Ghachi M, Deghmane AE, Szatanik M, et al. Penicillin resistance compromises Nod1-dependent proinflammatory activity and virulence fitness of Neisseria meningitidis. Cell Host Microbe. 2013 Jun 12;13(6):735-45. PubMed PMID: 23768497. Epub 2013/06/19. eng.

24. Lemee L, Hong E, Etienne M, Deghmane AE, Delbos V, Terrade A, et al. Genetic diversity and levels of expression of factor $\mathrm{H}$ binding protein among carriage isolates of Neisseria meningitidis. PLoS One. 2014;9(9):e107240. PubMed PMID: 25247300. Pubmed Central PMCID: 4172500. Epub 2014/09/24. eng.

25. Dabernat H, Delmas C, Seguy M, Pelissier R, Faucon G, Bennamani S, et al. Diversity of betalactam resistance-conferring amino acid substitutions in penicillin-binding protein 3 of Haemophilus influenzae. Antimicrob Agents Chemother. 2002 Jul;46(7):2208-18. PubMed PMID: 12069976.

26. Ubukata K, Shibasaki Y, Yamamoto K, Chiba N, Hasegawa K, Takeuchi Y, et al. Association of amino acid substitutions in penicillin-binding protein 3 with beta-lactam resistance in betalactamase-negative ampicillin-resistant Haemophilus influenzae. Antimicrob Agents Chemother. 2001 Jun;45(6):1693-9. PubMed PMID: 11353613.

27. Leung AKC, Wong AHC. Acute Otitis Media in Children. Recent Pat Inflamm Allergy Drug Discov. 2017;11(1):32-40. PubMed PMID: 28707578. Epub 2017/07/15. eng.

28. Ubukata K, Morozumi M, Sakuma M, Takata M, Mokuno E, Tajima T, et al. Etiology of Acute Otitis Media and Characterization of Pneumococcal Isolates After Introduction of 13-Valent Pneumococcal Conjugate Vaccine in Japanese Children. Pediatr Infect Dis J. 2018 Jun;37(6):598-604. PubMed PMID: 29474258. Epub 2018/02/24. eng. 
Table 1 Distribution of the invasive and non-invasive cultured isolates according to their susceptibility to ampicillin and to their serotypes.

\begin{tabular}{|c|c|c|c|c|c|c|c|c|c|c|c|c|c|}
\hline Serotypes (invasive isolates) & $\mathrm{a}$ & $\mathrm{b}$ & $\mathrm{d}$ & $\mathrm{e}$ & $\mathrm{f}$ & $\begin{array}{c}\text { All } \\
\text { typeable }\end{array}$ & NT & All & MIC50 & MIC90 & RANGE & $\begin{array}{l}\text { Geometric } \\
\text { mean MIC }\end{array}$ & $95 \%$ CI \\
\hline Ampicillin suceptible (BLNAS) & 7 & 8 & 1 & 2 & 12 & 30 & 74 & 104 & 0.25 & 0.5 & $0.016-1$ & 0.264 & $0.231-0.302$ \\
\hline Ampicillin resistant (All) & 0 & 2 & 0 & 2 & 0 & 4 & 28 & 32 & 12 & 256 & $1.5-256$ & 20.31 & $9.168-45.01$ \\
\hline BLNAR & 0 & 0 & 0 & 0 & 0 & 0 & 9 & 9 & 1.5 & 256 & $1.5-256$ & 2.831 & $0.770-10.41$ \\
\hline BLPAR & 0 & 2 & 0 & 2 & 0 & 4 & 19 & 23 & 64 & 256 & $2-256$ & 43.92 & $19.33-99.83$ \\
\hline $\begin{array}{l}\text { Serotypes (non-invasive } \\
\text { isolates) }\end{array}$ & $\mathrm{a}$ & $\mathrm{b}$ & $\mathrm{d}$ & $\mathrm{e}$ & $\mathrm{f}$ & $\begin{array}{c}\text { All } \\
\text { typeable }\end{array}$ & NT & All & MIC50 & MIC90 & RANGE & $\begin{array}{l}\text { Geometric } \\
\text { mean MIC }\end{array}$ & $95 \% \mathrm{CI}$ \\
\hline Ampicillin suceptible (BLNAS) & 0 & 0 & 0 & 0 & 1 & 1 & 48 & 49 & 0.38 & 0.5 & $0.064-1$ & 0.399 & $0.335-0.474$ \\
\hline Ampicillin resistant (All) & 0 & 0 & 0 & 0 & 0 & 0 & 51 & 51 & 8 & 256 & $1.5-256$ & 16.34 & $9.894-30.01$ \\
\hline BLNAR & 0 & 0 & 0 & 0 & 0 & 0 & 24 & 24 & 2 & 256 & $1.5-12$ & 2.351 & $1.857-2.977$ \\
\hline BLPAR & 0 & 0 & 0 & 0 & 0 & 0 & 27 & 27 & 256 & 256 & $6-256$ & 91.5 & $51.27-163$ \\
\hline
\end{tabular}


Table 2. Mutations and groups of ftsI (group1 in black, group2 in blue, group3 in green and group4 in red)

\begin{tabular}{|c|c|c|c|c|c|c|c|c|c|c|c|c|}
\hline $\begin{array}{l}\text { allele } \\
\text { id }\end{array}$ & D350N & S357N & $\mathrm{A} 368 \mathrm{~T}$ & M377I & $\mathrm{S} 385 \mathrm{~T} / \mathrm{N}$ & L389F & A437S & I449V & G490E & $\mathrm{A} 502 \mathrm{~T} / \mathrm{V}$ & R517H & N526K \\
\hline $4^{\mathrm{a}}$ & $\mathrm{NO}$ & $\mathrm{NO}$ & $\mathrm{NO}$ & $\mathrm{NO}$ & $\mathrm{NO}$ & $\mathrm{NO}$ & $\mathrm{NO}$ & $\mathrm{NO}$ & $\mathrm{NO}$ & $\mathrm{NO}$ & $\mathrm{NO}$ & $\mathrm{NO}$ \\
\hline $6^{\mathrm{b}}$ & D350N & $\mathrm{NO}$ & $\mathrm{NO}$ & $\mathrm{NO}$ & $\mathrm{NO}$ & $\mathrm{NO}$ & $\mathrm{NO}$ & $\mathrm{NO}$ & $\mathrm{NO}$ & $\mathrm{NO}$ & $\mathrm{NO}$ & $\mathrm{NO}$ \\
\hline 28 & $\mathrm{NO}$ & $\mathrm{NO}$ & $\mathrm{A} 368 \mathrm{~T}$ & $\mathrm{NO}$ & $\mathrm{NO}$ & $\mathrm{NO}$ & $\mathrm{NO}$ & $\mathrm{NO}$ & $\mathrm{NO}$ & $\mathrm{NO}$ & $\mathrm{NO}$ & $\mathrm{NO}$ \\
\hline 41 & $\mathrm{NO}$ & $\mathrm{NO}$ & $\mathrm{NO}$ & $\mathrm{NO}$ & $\mathrm{NO}$ & $\mathrm{NO}$ & $\mathrm{NO}$ & $\mathrm{NO}$ & $\mathrm{NO}$ & A502T & $\mathrm{NO}$ & $\mathrm{NO}$ \\
\hline $50^{c}$ & D350N & $\mathrm{NO}$ & $\mathrm{NO}$ & $\mathrm{NO}$ & $\mathrm{NO}$ & $\mathrm{NO}$ & $\mathrm{A} 437 \mathrm{~S}$ & $\mathrm{NO}$ & $\mathrm{NO}$ & $\mathrm{NO}$ & $\mathrm{NO}$ & $\mathrm{NO}$ \\
\hline $52^{\mathrm{d}}$ & $\mathrm{NO}$ & $\mathrm{NO}$ & $\mathrm{NO}$ & $\mathrm{NO}$ & $\mathrm{NO}$ & $\mathrm{NO}$ & $\mathrm{NO}$ & $\mathrm{NO}$ & $\mathrm{NO}$ & $\mathrm{NO}$ & $\mathrm{R} 517 \mathrm{H}$ & $\mathrm{NO}$ \\
\hline 94 & D350N & $\mathrm{NO}$ & $\mathrm{NO}$ & $\mathrm{NO}$ & $\mathrm{NO}$ & $\mathrm{NO}$ & $\mathrm{NO}$ & $\mathrm{NO}$ & $\mathrm{NO}$ & $\mathrm{NO}$ & $\mathrm{R} 517 \mathrm{H}$ & $\mathrm{NO}$ \\
\hline 5 & $\mathrm{NO}$ & $\mathrm{NO}$ & $\mathrm{NO}$ & $\mathrm{NO}$ & $\mathrm{NO}$ & $\mathrm{NO}$ & $\mathrm{NO}$ & I449V & $\mathrm{NO}$ & $\mathrm{NO}$ & $\mathrm{NO}$ & N526K \\
\hline 20 & $\mathrm{NO}$ & $\mathrm{NO}$ & $\mathrm{NO}$ & $\mathrm{NO}$ & $\mathrm{NO}$ & $\mathrm{NO}$ & $\mathrm{NO}$ & $\mathrm{NO}$ & $\mathrm{NO}$ & $\mathrm{NO}$ & $\mathrm{NO}$ & N526K \\
\hline $1^{\mathrm{e}}$ & D350N & $\mathrm{NO}$ & $\mathrm{NO}$ & M377I & $\mathrm{NO}$ & $\mathrm{NO}$ & $\mathrm{NO}$ & $\mathrm{NO}$ & $\mathrm{NO}$ & A502V & $\mathrm{NO}$ & N526K \\
\hline 21 & $\mathrm{NO}$ & $\mathrm{NO}$ & $\mathrm{NO}$ & $\mathrm{NO}$ & $\mathrm{NO}$ & $\mathrm{NO}$ & $\mathrm{NO}$ & $\mathrm{NO}$ & $\mathrm{NO}$ & $\mathrm{A} 502 \mathrm{~T}$ & $\mathrm{NO}$ & N526K \\
\hline 11 & D350N & $\mathrm{NO}$ & $\mathrm{NO}$ & $\mathrm{NO}$ & $\mathrm{NO}$ & $\mathrm{NO}$ & $\mathrm{NO}$ & $\mathrm{NO}$ & $\mathrm{NO}$ & A502V & $\mathrm{NO}$ & N526K \\
\hline 23 & D350N & $\mathrm{NO}$ & $\mathrm{NO}$ & M377I & $\mathrm{NO}$ & $\mathrm{NO}$ & $\mathrm{NO}$ & $\mathrm{NO}$ & G490E & A502V & $\mathrm{NO}$ & N526K \\
\hline $42^{f}$ & $\mathrm{NO}$ & $\mathrm{NO}$ & $\mathrm{NO}$ & $\mathrm{NO}$ & $\mathrm{NO}$ & $\mathrm{NO}$ & $\mathrm{NO}$ & $\mathrm{NO}$ & G490E & A502V & $\mathrm{NO}$ & N526K \\
\hline 91 & $\mathrm{NO}$ & $\mathrm{NO}$ & $\mathrm{NO}$ & $\mathrm{NO}$ & $\mathrm{NO}$ & $\mathrm{NO}$ & $\mathrm{NO}$ & $\mathrm{NO}$ & G490E & $\mathrm{NO}$ & $\mathrm{NO}$ & N526K \\
\hline 40 & D350N & S357N & $\mathrm{NO}$ & M377I & S385T & L389F & $\mathrm{NO}$ & $\mathrm{NO}$ & $\mathrm{NO}$ & $\mathrm{NO}$ & $\mathrm{NO}$ & N526K \\
\hline 87 & D350N & S357N & $\mathrm{NO}$ & M377I & S385T & L389F & $\mathrm{NO}$ & $\mathrm{NO}$ & $\mathrm{NO}$ & $\mathrm{NO}$ & $\mathrm{NO}$ & N526K \\
\hline 16 & D350N & S357N & $\mathrm{NO}$ & M377I & S385T & L389F & $\mathrm{NO}$ & $\mathrm{NO}$ & $\mathrm{NO}$ & A502T & $\mathrm{NO}$ & N526K \\
\hline 19 & D350N & S357N & $\mathrm{NO}$ & M377I & S385T & L389F & $\mathrm{NO}$ & $\mathrm{NO}$ & G490E & $\mathrm{NO}$ & $\mathrm{NO}$ & N526K \\
\hline $32^{g}$ & D350N & S357N & $\mathrm{NO}$ & M377I & S385T & $\mathrm{NO}$ & $\mathrm{NO}$ & $\mathrm{NO}$ & $\mathrm{NO}$ & $\mathrm{NO}$ & $\mathrm{R} 517 \mathrm{H}$ & $\mathrm{NO}$ \\
\hline 26 & D350N & S357N & $\mathrm{NO}$ & M377I & S385T & L389F & $\mathrm{NO}$ & $\mathrm{NO}$ & $\mathrm{NO}$ & $\mathrm{NO}$ & $\mathrm{R} 517 \mathrm{H}$ & $\mathrm{NO}$ \\
\hline
\end{tabular}

${ }^{\text {a }}$ The following alleles also shared the same amino-acid sequence as the allele $4(8,10,15,18,27$, $29,31,35,37,46,53,59,63$ and 99 ).

${ }^{\mathrm{b}}$ The following alleles also shared the same amino-acid sequence as the allele 6 (12, 39 and 55).

${ }^{c}$ Allele 54 shared the same amino-acid sequence as the allele 50.

${ }^{d}$ Allele 101 shared the same amino-acid sequence as the allele 52.

${ }^{\text {e }}$ Allele 96 shared the same amino-acid sequence as the allele 1.

${ }^{f}$ Allele 47 shared the same amino-acid sequence as the allele 42.

${ }^{\mathrm{g}}$ Allele 33 shared the same amino-acid sequence as the allele 32. 
Table 3. MIC of beta-lactam antibiotics according to the group of $f t s I$ sequence among invasive beta lactamase negative isolates

\begin{tabular}{ccccccc}
$\begin{array}{c}f t s I \\
\text { groups }\end{array}$ & Antibiotics & $\begin{array}{c}\text { Number of } \\
\text { isolates }\end{array}$ & $\begin{array}{c}\text { Minimum } \\
\text { MIC }\end{array}$ & $\begin{array}{c}\text { Maximum } \\
\text { MIC }\end{array}$ & $\begin{array}{c}\text { Geometric } \\
\text { mean of } \\
\text { MIC }\end{array}$ & $\begin{array}{c}\text { 95\% CI of } \\
\text { geometric mean }\end{array}$ \\
\hline Group1 & & 60 & 0.016 & 0.500 & 0.214 & $0.181-0.254$ \\
Group2 & Ampicillin & 26 & 0.032 & 0.500 & 0.270 & $0.220-0.332$ \\
Group3 & 16 & 0.190 & 2.000 & 0.868 & $0.619-1.216$ \\
Group4 & & 7 & 0.500 & 256.0 & 2.192 & $0.302-15.92$ \\
\hline Group1 & & 60 & 0.016 & 1.000 & 0.455 & $0.373-0.554$ \\
Group2 & Amoxicillin & 26 & 0.094 & 1.000 & 0.520 & $0.423-0.640$ \\
Group3 & & 16 & 0.380 & 6.000 & 1.857 & $1.306-2.640$ \\
Group4 & & 7 & 0.750 & 48.00 & 3.394 & $0.775-14.85$ \\
\hline Group1 & Amoxicillin+ & 60 & 0.016 & 5.000 & 0.461 & $0.373-0.571$ \\
Group2 & Clavulanic & 16 & 0.094 & 1.000 & 0.496 & $0.408-0.603$ \\
Group3 & acid & 7 & 0.750 & 4.000 & 1.719 & $1.303-2.268$ \\
Group4 & & 0.500 & 256.0 & 3.536 & $0.482-25.93$ \\
\hline Group1 & & 60 & 0.002 & 0.047 & 0.0145 & $0.012-0.017$ \\
Group2 & Cefotaxim & 26 & 0.003 & 0.064 & 0.0255 & $0.020-0.032$ \\
Group3 & 16 & 0.008 & 0.094 & 0.045 & $0.033-0.062$ \\
Group4 & & 7 & 0.125 & 0.750 & 0.316 & $0.162-0.617$ \\
\hline
\end{tabular}




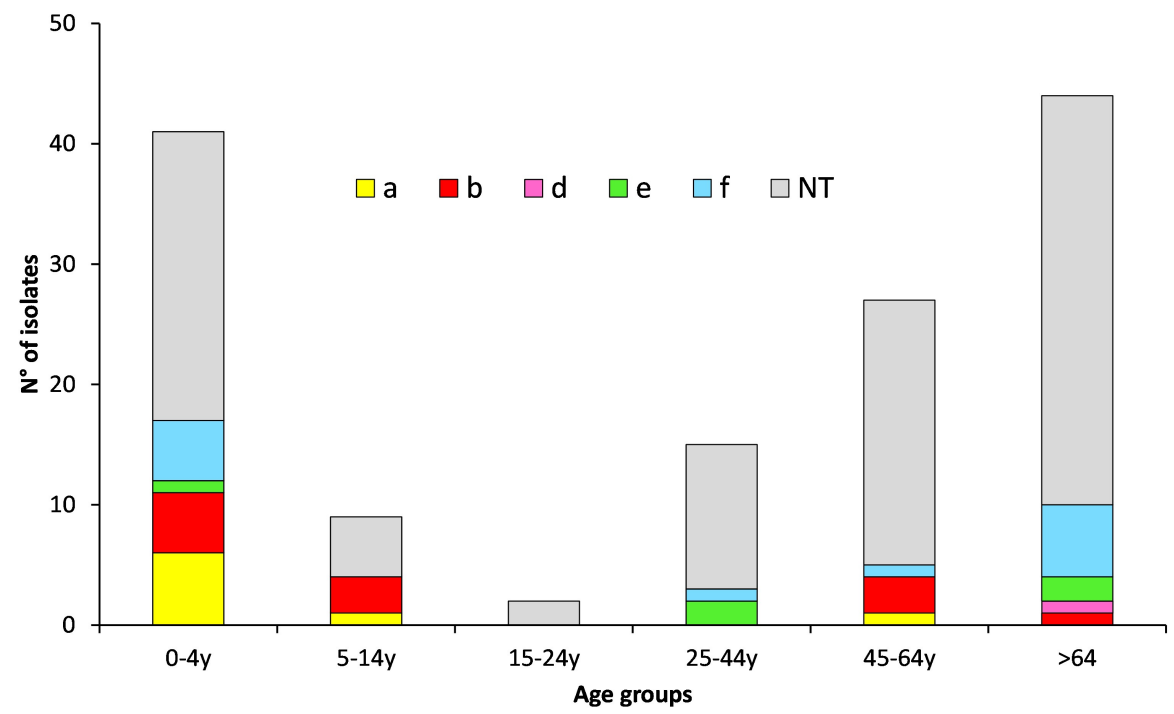

Figure 1.

Distribution of invasive isolates according to groups of age and serotypes 


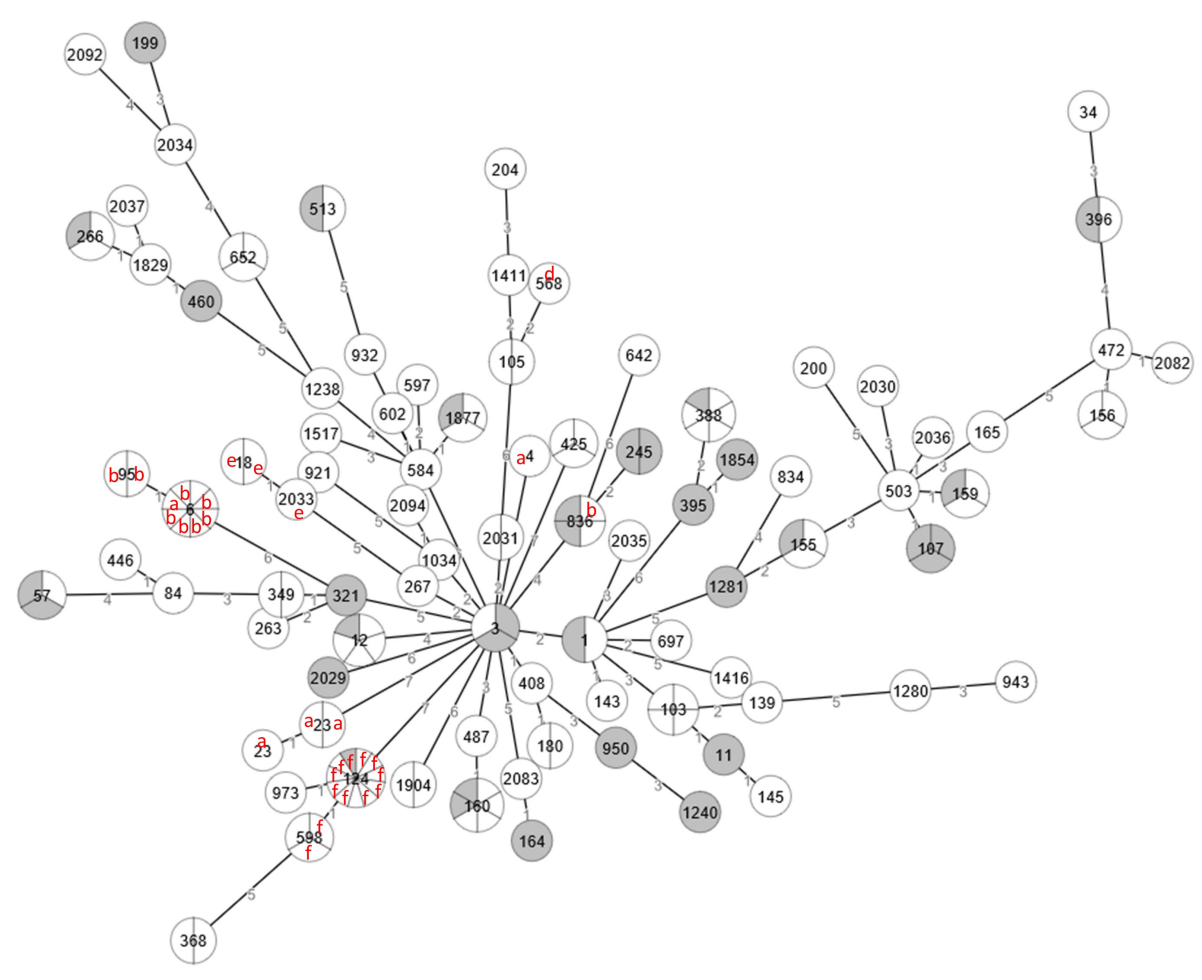

Figure. 2

A grapeTree based on the 7 MLST loci from 122 genome of invasive and the 34 carriage isolates of $H$. influenzae from this study. The nodes were drawn to scale according to the number of isolates ( indicated by the pie chart) of each node. The white node corresponded to invasive isolates and the grey nodes to non-invasive isolates. When the isolates were typeable, serotypes were shown by the corresponding letters in red. The other isolates (no indication) were nontypeable. The ST corresponding to each node was indicated inside the node. UA (Unassigned) corresponded to ST with non-assigned ST in the PUBMLST. The branches between the nodes were drawn to scale and the number of different alleles between the two connected nodes is indicated on the branch. 


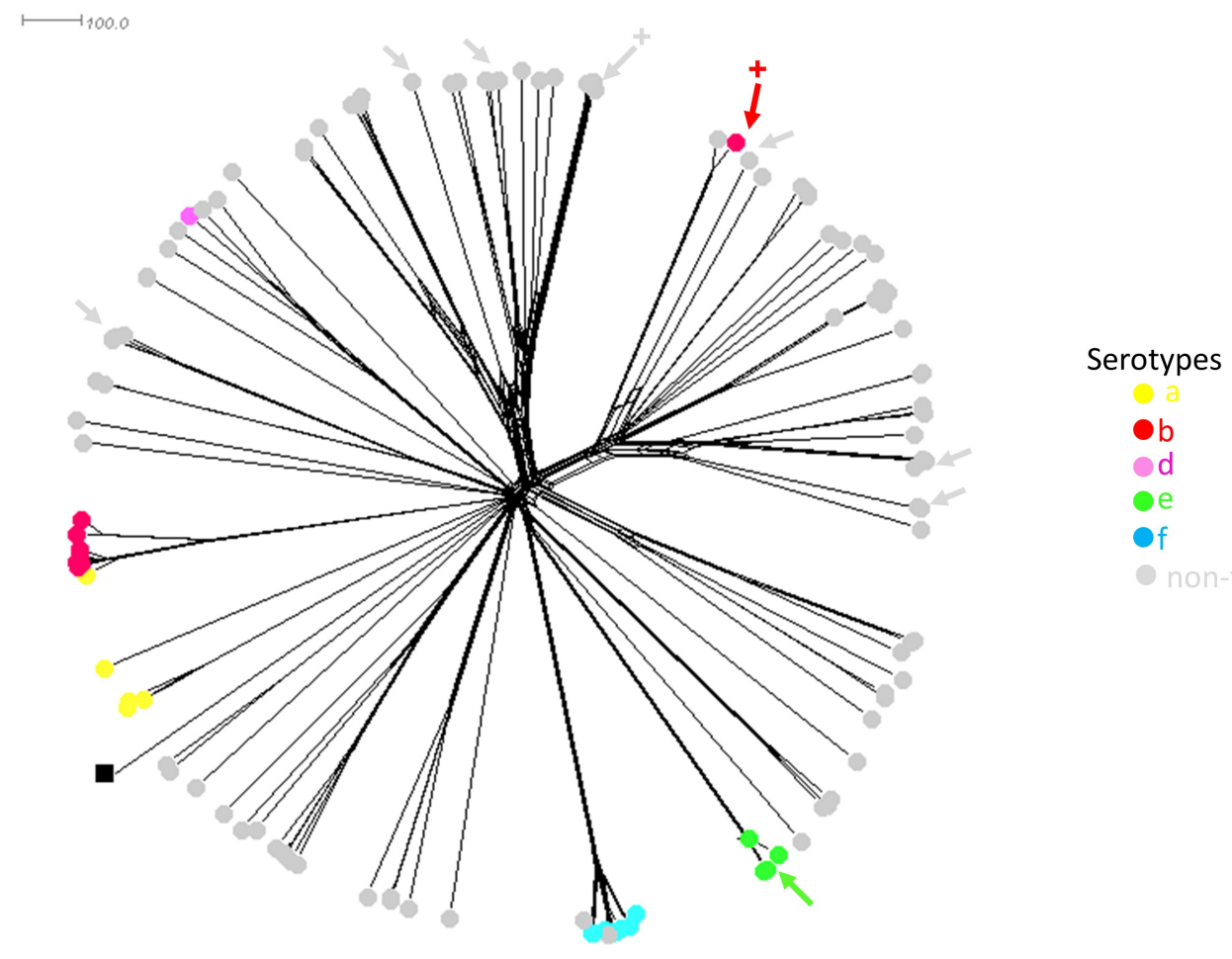

Figure 3.

A neighbour-network based on allelic profiles all the 130 invasive isolates compared to the annotated loci of the reference strain Rd KW20 (black square). Individual isolate is represented by circles and the colour of the circle indicates the serotype of the corresponding isolate. The arrows indicate cefotaxim resistant isolates (colours of the arrows are according to serotypes) that all belonged to group 4 ftsI (see Table 2). (+) indicate that the corresponding cefotaxim resistant isolate also produces a beta-lactamase. 


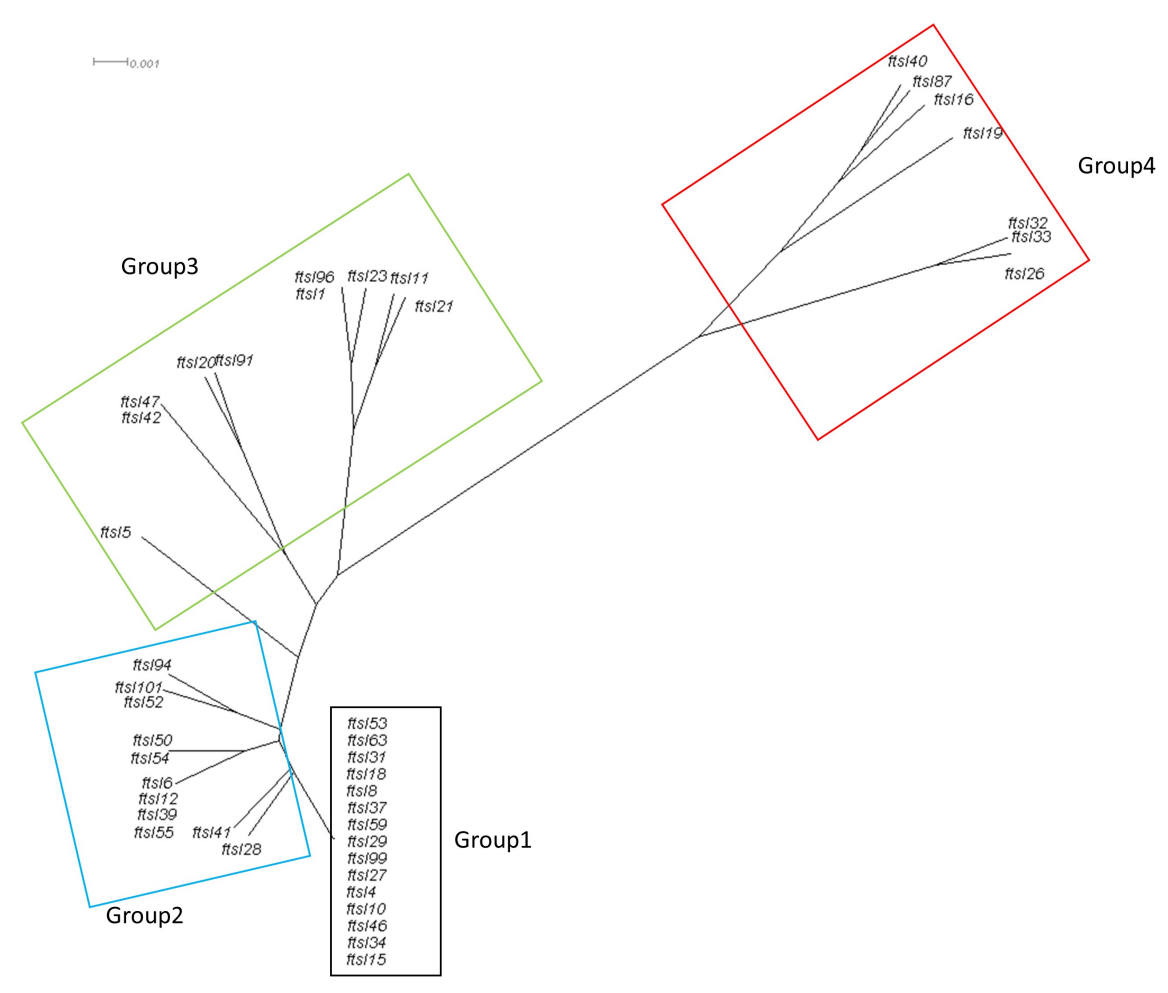

Figure 4.

Phylogenetic Tree of the ftsI based on the sequence CLUSTALW multiple alignment of amino-acid sequences deduced of the DNA sequences of all ftsI alleles defined among the invasive isolates of this study. The tree was visualized by SplitsTree 4 as described in the Methods section. The 4 ftsI groups described in this study are shown in rectangles (colours are according to Table 2). 